\title{
EDITORIAL
}

\section{ERGONOMIA: SOLUÇÕES E PROPOSTAS PARA UM TRABALHO MELHOR}

“Ergonomia: soluções e propostas para um trabalho melhor" foi o tema ABERGO 2008 - $15^{\circ}$ Congresso Brasileiro de Ergonomia - ocorrido na cidade de Porto Seguro - Bahia, no período de 2 a 6 de novembro de 2008. 0 conteúdo desta edição especial da revista Produção está composto de 11 artigos selecionados a partir de comunicações apresentadas no congresso, acrescido de dois artigos submetidos regularmente a revista. 0 evento incluiu sete palestrantes internacionais, 300 artigos apresentados em 65 sessões técnicas e 44 posters. A seleção para esta publicação ocorreu em duas etapas: [i] seleção dos artigos que alcançaram os maiores escores na revisão dos avaliadores do congresso e [iii] re-submissão dos artigos selecionados, a partir dos critérios editoriais da revista Produção, para serem avaliados por um corpo de avaliadores ad-hoc composto para este número especial.

Apresentar soluções e propostas para um trabalho melhor é o objetivo maior da ergonomia. A ergonomia é uma disciplina que promove uma abordagem holística e centrada no ser humano para o design de sistemas de trabalho que considera relevante os fatores físicos, cognitivos, sociais, organizacionais e ambientais (GRANDJEAN, 1986; WILSON e CORLLET, 1995; SANDERS e McCORMICK, 1993; CHAPANIS, 1999; SALVENDY, 1997; VICENTE, 2004; STANTON et al. 2004).

Os artigos aqui presentes abordam diversos temas e fornecem uma boa referência da amplitude da aplicação da ergonomia buscando propostas e soluções para um trabalho melhor. Visualiza-se aqui a aplicação da ergonomia contemporânea como entendida por Karwowski (2005): uma disciplina que se foca na natureza das interações do ser humano com os artefatos, a partir de uma perspectiva unificada da ciência, engenharia, design, tecnologia e gerenciamento da compatibilidade humano-sistema, incluindo uma variedade de produtos, processos e ambientes naturais e artificiais.

Com o avanço da tecnologia o trabalho humano muitas vezes se dá em ambientes complexos. A utilização da ergonomia para a análise de sistemas complexos, particularmente na área de aviação, vem ocorrendo desde a relação da ocorrência de acidentes associados ao uso de dispositivos de controle por parte do piloto (CHAPANIS, 1972). A tomada de decisão e os modos de controle cognitivos em sistemas complexos utilizados por pilotos de aeronaves devem ser analisados em função dos fatores de complexidade da atividade do piloto (veja HENRIQSON, CARIM JÚNIOR, SAURIN e AMARAL, nesta edição). Os acidentes, muitos dos quais em função de disfunções entre o ser humano e os sistemas complexos, apontam a área da ergonomia na aviação como sendo um dos temas a gerarem mais pesquisas num futuro próximo.

Ensinar é uma tarefa que acompanha o ser humano desde os primeiros registros pré-históricos. A aplicação da ergonomia na área do ensino é bastante vasta: envolve desde a análise da saúde e qualidade de vida que afeta o desempenho do professor (vide LEVY, NUNES SOBRINHO e SOUZA, nesta edição) até a análise dos materiais didáticos, especificamente, materiais digitais utilizando o conceito de usabilidade (GODOI e PADOVANI, nesta edição). Os aspectos físicos, relacionados a influência do ruído e da temperatura no desempenho ensino-aprendizagem também são estudos recorrentes na área da ergonomia. Gonçalves, Silva e Coutinho (nesta edição) concluem que o nível de ruído em sala de aula está acima dos padrões aceitáveis pela NBR 10.157, implicando em aumento da intensidade vocal e conseqüente fadiga do professor. Já Batiz, Morsch, 
Kasmirski Junior e Venske (nesta edição) apontam que as condições térmicas na sala de aula, afetam a atenção e a memória, com consequencias sobre o aprendizado do(a) aluno(a).

Outro aspecto da ergonomia evidenciado para a melhoria do trabalho humano é o estudo do ambiente no qual o trabalho é realizado, esta é a área da ergonomia do ambiente construído. As situações de risco e segurança nos espaços arquitetônicos e nas cidades têm possibilitado aos ergonomistas uma reflexão sobre o que pode ser melhorado e uma busca de soluções (SOARES, 2007). A ergonomia do ambiente construído estuda a utilização e a acessibilidade das edificações e dos ambientes públicos considerando a relação do ser humano com o ambiente, levando em conta as suas características e limitações físicas, culturais, cognitivas e emocionais. Nesta edição, Bins Ely e Silveira explicitam o estudo da acessibilidade espacial em unidades habitacionais em hotéis residenciais da cidade de Florianópolis e Fonseca e Rheingantz dão continuidade a análise de uma nova metodologia que avalia o processo de concepção de ambientes construídos. Considerando estes dois artigos, acrescido dos dois artigos citados no parágrafo anterior, que também enquadram-se no mesmo tema, temos quatro artigos na área de ambiente construído nesta edição especial. Assim, cumpre chamar a atenção para esta área de conhecimento, dentro da ergonomia, que encontra-se em franca ascenção, merecendo, inclusive um encontro específico, realizado anualmente.

A informação é uma característica essencial que encontra-se intrínsecamente relacionada a melhoria do trabalho humano. Para o ergonomista a aquisição e o processamento da informação são essenciais para 0 design e a análise da informação utilizada pelo usuário ou trabalhador, respeitando as suas diversidades em termos de habilidades e limitações. A informação digital encontra-se presente no nosso dia a dia. A ergonomia informacional e interação humano-computador são áreas consolidadas na ergonomia. Novas técnicas e novos modelos de análise são propostos para se analisar a comunicação do ser humano com os sistemas digitais (vide PADOVANI, SPINILLO e GOMES, nesta edição).

Os processos participativos são abordagens comuns na ergonomia contemporânea e objetivam o envolvimento dos trabalhadores nas condições de trabalho. Lima, Resende e Vasconcelos, nesta edição, discutem a importância das interações sócio-cognitivas no projeto de instrumentos de trabalho no nível de relações físicas. Os autores apresentam um estudo de caso de concepção de postos de trabalho centrado na atividade dos usuários a partir de um processo participativo. A análise e concepção de postos de trabalho pode ser considerada uma área tradicional na ergonomia, mas o enfoque participativo é relativamente recente. A macroergonomia é uma área em ascenção e possui um número bastante significativo de contribuições nos congressos da ABERGO.

Um dos aspectos nos quais a ergonomia atua visando a melhoria do trabalho humano é na prevenção de riscos e custos humanos do trabalho. Para a ergonomia o risco compreende uma percepção multi-dimensional envolvendo fatores psicológicos, sociais e culturais (WILLIAM, 2006). A análise dos critérios de prevenção de riscos nas atividades dos trabalhadores diante das exigências de produtividade, qualidade e flexibilidade na indústria algumas vezes vão de encontro aos aspectos de saúde e segurança dos trabalhadores (vide LIMA e ECHTERNACHT, nesta edição).

Já os custos humanos do trabalho se expressam através mortes, mutilações, lesões permanentes e temporárias, doenças e fadiga, decorrentes dos acidentes e incidentes, e da carga de trabalho (MORAES e MONT'ALVÃO, 2003). Assim, para a ergonomia, a melhoria do trabalho humano envolve a redução dos custos humanos do trabalho. Neste sentido, neste número especial, Teixeira, Torres, Moro e Merino investigam queixas músculo-esqueléticas associadas às inadequações ergonômicas de postos de trabalho a partir do descumprimento da NR-17; Regis Filho, Michels e Sell analisam os aspectos biomecânicos dos distúrbios ósteo-musculares relacionados ao trabalho (DORTs) nas atividades do cirurgião-dentista e Ballardin e Guimarães avaliam a carga de trabalho dos operadores de uma empresa distribuidora de derivados de petróleo. Cumpre observar que, assim como a análise e concepção de postos de trabalho, a área de riscos e custos humanos no trabalho é uma área de estudo bastante consolidada na ergonomia industrial, sendo esta a terceira área de maior incidência de trabalhos científicos nos congressos da ABERGO (SOARES, 2006).

Diversas soluções e propostas para um trabalho melhor, tema do ABERGO 2008, foram descritas nos artigos que compõem esta edição especial da Revista Produção. Sem dúdiva este é um marco para a área da ergonomia dentro da engenharia de produção e solidifica a parceria entre a ABERGO - Associação Brasileira de Ergonomia e a ABEPRO - Associação Brasileira de Engenharia de Produção.

\section{EDITOR CONVIDADO:}

\section{Marcelo Soares}

Ex-Presidente da ABERGO

Universidade Federal de Pernambuco

E-mail: marcelo2 @nlink.com.br 


\section{REFERÊNCIAS}

CHAPANIS, A. A engenharia e o relacionamento ser humano-máquina. São Paulo: Atlas, 1972.

CHAPANIS, A. The chapanis chronicles: 50 years of human factors research, education, and designer. Santa Barbara: Aegean, 1999.

GRANDJEAN, E. Fitting the task to the man. London: Taylor \& Francis, 1986.

KARWOWSKI, W. Ergonomics and human factors: the paradigms for science, engineering, design, technology, and management of human. Compatible systems. Ergonomics, v. 48, n. 5, p. 436-463, 2005.

MORAES, A.; MONT'ALVÃO, C. Ergonomia: conceitos e aplicações. 3 ed. Rio de Janeiro: Editora 2AB, 2003.
SALVENDY, G. Handbook of human factors and ergonomics. 2 ed. New York: Wiley, 1997.

SANDERS, M. M.; MCCORMICK, E. J. Human factors in engineering and design. 7 ed. New York: Mcgraw-Hill, 1993.

SOARES, M. M. Ergonomics in Latin America: background, trends and challenges. Applied Ergonomics, n. 37, p. 555-561, 2006.

SOARES, M. M. Atualidades da ergonomia no Brasil e no mundo: uma visão geral. In: ENCONTRO NACIONAL DE ERGONOMIA DO AMBIENTE CONSTRUÍDO - ENEAC, 1., 2007, Recife. Anais... Recife: ABERGO, 2007.
STANTON, N. et al. Handbook of human factors and ergonomics methods. Boca Raton: CRC Press, 2004.

VICENTE, K. J. The human factors. New York: Routledge, 2004.

WILLIAM, D. J. Conceptualization of risk. In: KARWOWSKY, W. (Org.). International encyclopedia of ergonomics and human factors. 2 ed. New York: Taylor \& Francis, 2006. (CD-ROM)

WILSON, J. R.; CORLLET, E. N. Evaluation of human work: a practical ergonomics methodology. 2 ed. London: Taylor \& Francis, 1995. 
